\title{
The effect of oil heat treatment on biological, 뼀 mechanical and physical properties of bamboo
}

\author{
Xiaomeng Hao ${ }^{1}$, Qiuyi Wang ${ }^{1}$, Yihua Wang ${ }^{3}$, Xin Han ${ }^{1}$, Chenglong Yuan ${ }^{1}$, Yu Cao ${ }^{1}$, Zhichao Lou ${ }^{1,2^{*}}$ and \\ Yanjun $\mathrm{Li}^{i^{*}}$
}

\begin{abstract}
Bamboo is now widely used in construction, papermaking, textile, furniture and other fields because of its renewable, fast-growing, high-strength, high-yield and easy processing. However, compared with wood, bamboo and bamboo products are more vulnerable to damage by fungi and pests. An effective and eco-friendly method is urgently needed to improve their physical and chemical properties, decay resistance and anti-mildew properties, and hydrophobic properties. Here, bamboo was heated with methyl silicone oil. The effect of different temperatures $\left(140^{\circ} \mathrm{C}-200^{\circ} \mathrm{C}\right)$ and different times ( $2 \mathrm{~h}-6 \mathrm{~h}$ ) on the properties of bamboo was studied systematically, including chemical composition, physical and mechanical properties, surface wettability, decay resistance and anti-mildew property. No starch granules were observed inside the parenchymal cell lumen of bamboo specimen heat treated at $200{ }^{\circ} \mathrm{C}$ for $6 \mathrm{~h}$. And with the increase of heat treatment temperature and time, the content of cellulose and hemicellulose decreases gradually while relative content of lignin increases due to its better thermal stability. Accordingly, the surface wettability decreases due to the changes of the surface functional groups and micro-morphologies. Under the condition of oil heat treatment at $160^{\circ} \mathrm{C}$ for $2 \mathrm{~h}$, the compressive strength parallel to grain of bamboo samples reach the maximum of $109.52 \mathrm{MPa}$. With further increase of heating temperature, the corresponding compressive strength decreases. The resulted bending strength and $\mathrm{MOE}$ both display similar changing trend. However, the optimal parameter is at $180^{\circ} \mathrm{C}$ for $2 \mathrm{~h}$, with the highest bending strength and MOE values of $142.42 \mathrm{MPa}$ and 12,373.00 MPa, respectively. Finally, the decay resistance and anti-mildew property are dramatically enhanced with increased heat treatment temperature and time. All the corresponding changing mechanisms are investigated in depth and in detail. Our results provide comprehensive process parameters and micro-mechanism for the performance of oil heat treatment of bamboo, which can be used to guide the actual production.
\end{abstract}

Keywords: Oil heat treatment, Bamboo, Surface wettability, Physical and mechanical property, Decay resistance, Anti-mildew, Micro-mechanism, Three major components

\section{Introduction}

With the rapid economic growth of our country and the improvement of people's living standards, the demand for wood in the home decoration, furniture and construction industries is increasing. In the case of prominent contradiction between supply and demand of wood, bamboo is

\footnotetext{
*Correspondence: zc-lou2015@njfu.edu.cn; nfcm2018@163.com 1 Jiangsu Co-Innovation Center of Efficient Processing and Utilization of Forest Resources, College of Materials Science and Engineering, Nanjing Forestry University, Nanjing 210037, China

Full list of author information is available at the end of the article
}

an important substitute for wood. Bamboo has become an important raw material in the economic construction of countries all over the world [1,2]. Compared with wood, bamboo has been widely used in some fields as one of the important resources in biomass industry for its fast growth, easy propagation and short renovation [3-7]. Through 30 years development, bamboo industry has become one of the eco-friendly, high value-added, lowcarbon and sustainable industries with Chinese characteristics [8]. On average bamboo has $2-5 \%$ of starch, $1.5-6 \%$ of proteins, $2 \%$ of glucose and $2-3.5 \%$ of fat and
Springer Open

(c) The Author(s) 2021. This article is licensed under a Creative Commons Attribution 4.0 International License, which permits use, sharing, adaptation, distribution and reproduction in any medium or format, as long as you give appropriate credit to the original author(s) and the source, provide a link to the Creative Commons licence, and indicate if changes were made. The images or other third party material in this article are included in the article's Creative Commons licence, unless indicated otherwise in a credit line to the material. If material is not included in the article's Creative Commons licence and your intended use is not permitted by statutory regulation or exceeds the permitted use, you will need to obtain permission directly from the copyright holder. To view a copy of this licence, visit http://creativeco mmons.org/licenses/by/4.0/. 
wax. Among them, starch generally acts as the nutrient reserve of plants, but at the same time, it is the main food source of fungi, which makes fungi attack biomass. Compared with wood, bamboo and bamboo products are more vulnerable to be damaged by fungi and pests. Therefore, mildew and decay of bamboo restrict the applications of bamboo products in special environment. Meanwhile, the inherent disadvantages of bamboo such as hydrophilicity and dimensional instability seriously shorten its service life $[9,10]$. Thus, it is the key to find an effective and eco-friendly way to improve the physical and chemical properties, decay resistance and anti-mildew properties, and hydrophobic properties of bamboo.

In recent years, more and more scientists have paid attention to the modification of bamboo, and various treatment methods have been applied on bamboo to improve the corresponding anti-mildew property including $\gamma$-ray irradiation [11], nanotechnology [12], chemical impregnation $[13,14]$ and the thermal treatment $[15$, 16]. The gamma ray irradiation technology can not only sterilize, but also destroy the nutrients on the surface of bamboo. It is known that this method is efficient, pollution-free and has a low cost. However, high irradiation dose induces a decrease in the mechanical properties [17]. As reported, the introduction of nanotechnology can not only endow bamboo with new functions, but also further improve its properties. However, considering the easy leachability and high cost of modified nano-inorganic materials, it is not suitable for large-scale outdoor use [18]. Similarly, due to the anatomical characteristics of bamboo, the chemical agents cannot be immersed into its interior completely. Meanwhile, the chemical agents contain heavy metal ions, toxic monomers of organic compound and toxic organic solvents, which is detrimental to health and causes irreversible destruction to the environment [19]. Thermal modification of bamboo is a commercially viable technology. It utilizes heat as a medium to alter the structure and chemistry of bamboo to achieve desired properties. From the economic, environmental and sustainable point of view, heat treatment is considered to be an efficient way to solve this problem.

High temperature heat treatment refers to modification of biomass in protective gas environment or liquid medium at $160-250{ }^{\circ} \mathrm{C}$ [20]. Hemicellulose degrades in high temperature, resulting in a decrease in hygroscopicity and water absorption. As a result, the corresponding dimensional stability, decay resistance and anti-mildew property of bamboo are improved [21, 22]. Previous researches indicate that the extraction rate of hemicellulose increases with the increase of temperature [23], while the corresponding mechanical properties are the opposite [24]. Zhao [25] and Zhang [26] found that the mechanical properties of moso bamboo decreased significantly when the steam heat treatment temperature increased up to $200{ }^{\circ} \mathrm{C}$. The changes of temperature and time had no significant effect on the bending properties of moso bamboo. Among the heat treatment methods, hydrothermal treatment and steam heat treatment are both dominant [27]. In contrast, the steam needs a special pressurized environment, and it is a high-energy consumption method. Besides, similar to the hydrothermal one, the resulted water has certain pollution which needs further treatments. The performance of modified wood and bamboo has certain limitations. In recent years, oil heat treatment is considered to be a green and effective method for biomass modification. Various industrial vegetable oils (such as linseed oil, palm oil, rapeseed oil and soybean oil), cogasin and mineral oil (such as silicone oil and paraffin oil) are used as heat medium to modify wood [28, 29]. Among them, silicone oil is an excellent electrical insulator with high thermal stability and good heat transfer characteristics, which is widely used in oil bath heating [30, 31]. The study on the thermal modification of bamboo with methyl silicone oil is poor [32], especially on the macroscopic and microscopic characteristics, physical and chemical properties, decay resistance and anti-mildew property, hydrophobic property of products obtained by different process parameters, and the relationship among properties.

In this paper, the effects of oil heat treatment on bamboo properties were systematically studied, including chemical composition, physical and mechanical properties, surface wettability, decay resistance, anti-mildew property and the relationship among the changes of microstructure, chemical composition and physical and mechanical properties. The heat medium was methyl silicone oil, the temperature was from $140{ }^{\circ} \mathrm{C}$ to $200{ }^{\circ} \mathrm{C}$ and the time was from 2 to $6 \mathrm{~h}$.

\section{Materials and methods Materials}

Moso bamboo of 5 years old was obtained from Changhua, Hangzhou. The defect-free bamboo samples of $300 \mathrm{~mm} \times 30 \quad \mathrm{~mm} \times 8 \quad \mathrm{~mm}$ (longitudinal $\times$ tangential $\times$ radial), were cut $2 \mathrm{~m}$ away from the root. Thermally oil modified bamboo samples were divided into 12 treatment groups in addition to one group set as control (untreated) samples. To be mentioned, all the tests were repeated 8 times and the average results were collected and analyzed.

\section{Oil heat treatment}

Bamboo samples were oven-dried at $105^{\circ} \mathrm{C}$ until weight constancy was achieved. After this step, samples were transferred and immersed in a heated oil bath at $140{ }^{\circ} \mathrm{C}$, $160{ }^{\circ} \mathrm{C}, 180{ }^{\circ} \mathrm{C}$ and $200{ }^{\circ} \mathrm{C}$ for $2 \mathrm{~h}, 4 \mathrm{~h}$ and $6 \mathrm{~h}$ at each 
defined temperature, respectively. During heat treatment of samples, the oil bath was covered and after the oil heat treatment, the samples were wiped and cooled.

\section{Scanning electron microscopy (SEM)}

The morphology of samples was characterized by TM3030 (Opton, UK) scanning electron microscopy. The middle part of the bamboo is cut off, the surface is smoothened, and finally dried in an oven at $105{ }^{\circ} \mathrm{C}$. In order to improve the conductivity of bamboo, conductive adhesive was used to fix the bamboo on the aluminum specimen rack. The vacuum coating instrument was used to spray gold to increase the conductivity of specimen. The changes of starch particles and surface structure of bamboo samples with different oil heat treatment were observed by scanning electron microscope.

\section{Atomic force microscopy (AFM)}

The resulted morphologies of the samples were characterized by an Asylum Research MFP-3D Bio AFM machine from Oxford Instruments Company. Silicon cantilever tips with a spring constant of $26 \mathrm{~N} / \mathrm{m}$ were used (Model: AC160TS-RS Olympus, Japan). Its corresponding radius is $7 \mathrm{~nm}$. All the images were taken under AC Air Topography format with a scanning rate of $0.5 \mathrm{~Hz}$. The $1024 \times 1024$ points AFM images were processed by software from Oxford. The bamboo slice is divided into two parts, one part is placed in the oil environment for heat treatment, the other is kept in air during the oil heat treatment. Before scanning, the treated samples were washed slightly by water and dried, and then placed in AFM machine. The AFM tip was moved to the interface between the oil residue and the bare bamboo surface under the inverted microscope, and then AFM scanning was performed.

\section{X-ray diffraction (XRD)}

A step-by-step scanning method with powder X-ray diffractometer T-6000 (Malvern Panalytical, UK) was used. The scanning angle was $5^{\circ}$ to $50^{\circ}$ and the scanning speed was $2^{\circ} / \mathrm{min}$. The crystallinity $(\mathrm{Cr} I)$ and lattice spacing of cellulose before and after oil heat treatment was calculated by Segal method:

$$
\begin{aligned}
& C r I=\left(\frac{I_{002}-I_{a m}}{I_{002}}\right) \times 100 \%, \\
& n \lambda=2 d \sin \theta,
\end{aligned}
$$

where $\mathrm{CrI}$ is the relative crystallinity; $d$ is the lattice spacing; $I_{002}$ is the maximum intensity of diffraction peak of crystal (002) plane; $I_{a m}$ is the diffraction intensity of amorphous; $n=1$ is the diffraction series; $\lambda$ is the wavelength of X-ray, which is $0.15406 \AA$, and $\theta$ is the peak position.

\section{Fourier transform infrared spectroscopy (FTIR)}

The spectra were determined by the VERTEX-80 V (Bruker, Germany) infrared spectrometer. Before determination, the dried bamboo powder was mixed with $\mathrm{KBr}$ and pressed into a thin sheet. The scanning range is $500-4000 \mathrm{~cm}^{-1}$, and the scanning times are 32 and the resolution is $4 \mathrm{~cm}^{-1}$. The thin sheet is placed in the Fourier infrared spectrometer for determination. Finally, the infrared spectrum was drawn for analysis.

\section{Major chemical composition test}

The contents of three major elements (cellulose, hemicellulose and lignin) in bamboo before and after treatment were determined by the National Renewable Energy Laboratory (NREL'S LAPS) [33]. The sugar content in the supernatant was determined by high-performance liquid chromatography (HPLC). $\mathrm{H}_{2} \mathrm{SO}_{4}$ solution was used as eluent at a flow rate of $0.6 \mathrm{~mL} / \mathrm{min}$.

\section{Surface wettability test}

The contact angles were determined by the liquid droplet method. The liquid measurement medium was deionized pure water and the measurements were performed at temperature $\left(20{ }^{\circ} \mathrm{C}\right)$ and $40 \%$ to $50 \% \mathrm{RH}$ with the help of a SCA20 (Dataphysics, Germany) Automatic Contact Angle Apparatus. The instantaneous static contact angle of droplet contacting the specimen surface for $0 \mathrm{~s}$ was recorded by computer. Three different positions were selected on each section for measurement. The average was the final result.

\section{Physical and mechanical properties test}

According to the national standard GB/T 15780-1995 "Testing methods for physical and mechanical properties of bamboos" [34], the compressive strength parallel to grain, bending strength and elastic modulus of samples before and after oil heat treatment were measured by DNS50 (Sinotest, China) electronic universal testing machine.

\section{Decay resistance test}

According to ASTM D1413-99 "Standard Test Method for Wood Preservatives by laboratory Soil-Block Cultures" [35], indoor decay resistance test was carried out with brown-rot fungi. The bamboo before and after oil heat treatment were made into samples with $20 \mathrm{~mm} \times 20 \mathrm{~mm} \times 8 \mathrm{~mm}$, followed by decay resistance tests. The decay resistance grade is evaluated by the mass loss of the bamboo samples before and after decay. The calculation method of the mass loss (ML) is shown in 
Table 1 Standard method for rating infection value of samples

\begin{tabular}{ll}
\hline Loss rate (\%) & Decay resistance grade \\
\hline $0-10$ & Strong decay resistance I \\
$11-24$ & Decay resistance II \\
$25-44$ & Slightly resistant to decay III \\
$>45$ & Not resistant to decay IV \\
\hline
\end{tabular}

Table 2 Rating for the infection value of mold growth on bamboo

\begin{tabular}{ll}
\hline Rate & Description \\
\hline 0 & No visible growth \\
1 & Mold covering up to $1 / 4$ of the surface \\
2 & Mold covering between $1 / 4$ and $1 / 2$ of the surface \\
3 & Mold covering between $1 / 2$ and $3 / 4$ of the surface \\
4 & Mold on greater than $3 / 4$ of the surface \\
\hline
\end{tabular}

Formula (3). The standard for assessing the decay resistance grade of the final test piece is shown in Table 1 :

$$
\mathrm{ML}=\frac{W_{1}-W_{2}}{W_{2}},
$$

where ML is the mass loss; $W_{1}, W_{2}$ is the mass of bamboo samples before and after corrosion, respectively.
Anti-mildew property test

According to GB/T 18261-2013 "Test method for antimildew agents in controlling wood mold and stain fungi" [36], the samples of $50 \mathrm{~mm} \times 20 \mathrm{~mm} \times 5 \mathrm{~mm}$ before and after oil heat treatment were made. There were no defects on the surface of samples (see Table 2).

\section{Results and discussion}

Effect of oil heat treatment on the microstructure of bamboo

The micromorphology of untreated bamboo in cross section and longitudinal section is shown in Fig. 1. The parenchyma cell wall of untreated bamboo is smooth as shown in Fig. 1a-c. The pits throughout the cell wall distribute evenly as circled by yellow short-dashed line in Fig. 1f. As we know, these pits are channels for exchanging nutrients and moisture among cells. Furthermore, a large number of starch granules as pointed by yellow arrows in Fig. 1c and $\mathrm{f}$ are observed in the cell lumen, which are supposed to be nutrients for the growth of mold.

Figure 2 presents the micro-morphologies of the cross section and longitudinal section of bamboo samples, which are treated with methyl silicone oil at $200{ }^{\circ} \mathrm{C}$ for $6 \mathrm{~h}$. As shown in Fig. 2a-c, the parenchyma cells of treated bamboo are obviously distorted and deformed as outlined by yellow dotted lines. Moreover, the gaps between adjacent cell walls increase as pointed by green
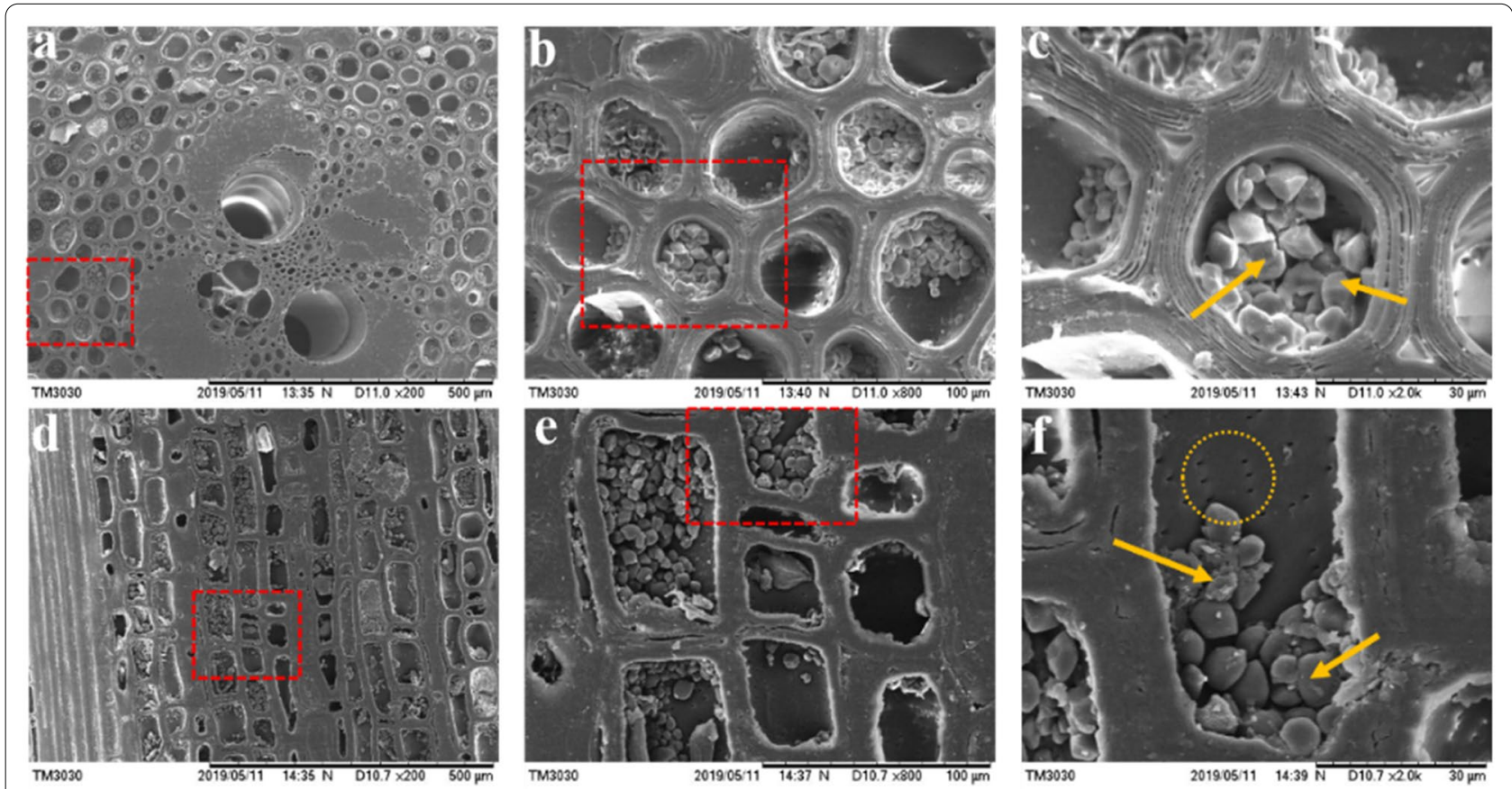

Fig.1 SEM images of untreated bamboo samples in a-c cross section and $\mathbf{d}$-f longitudinal section, respectively 

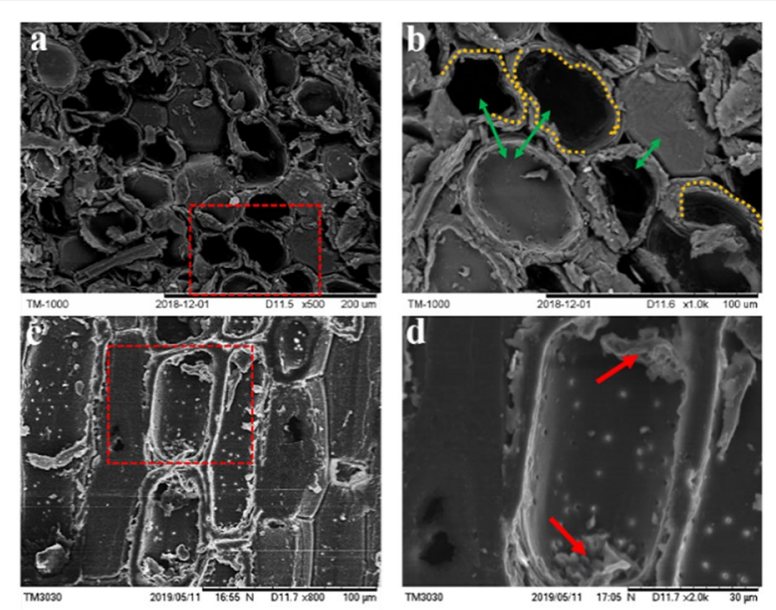

Fig.2 SEM images of oil heat-treated bamboo samples at $200{ }^{\circ} \mathrm{C}$ for 6 h. $\mathbf{a}, \mathbf{b}$ cross section, $\mathbf{c}$, $\mathbf{d}$ longitudinal section

arrows. All these observations indicate that the cell wall toughness of treated samples decreases. This is due to the fact that the hydration water evaporates during heat treatment processes, causing the internal stress. As a result, the dense structure of cell wall is destroyed. More importantly, the samples which are oil heat treated at $200{ }^{\circ} \mathrm{C}$ for $6 \mathrm{~h}$ have no starch granules inside the parenchymal cell lumen. This is attributed to their pyrolysis or melting loss under the condition of oil heat treatment. Accordingly, gelatinized starch can be observed in Fig. $1 \mathrm{~d}$ as pointed by red arrows. Besides, after oil heat treatment, the mixtures formed by condensations of starch and oil blocks the pits during the precipitation of molten materials. It is worth mentioning that the small oil molecules gradually enter into the crystallization area of starch granules during the heat treatment, resulting in swelling and collapse of starch granules. As a result, the pyrolysis and precipitation of starch molecules are accelerated.

\section{Effect of oil heat treatment on the crystallinity of cellulose}

XRD spectra of bamboo samples before and after oil heat treatment are shown in Fig. 3. Figure 3a shows the $\mathrm{X}$-ray diffraction profiles of untreated bamboo and the treated bamboo at 140, 160, 180 and $200{ }^{\circ} \mathrm{C}$ for $6 \mathrm{~h}$. Figure $3 \mathrm{~b}$ is the XRD spectra of untreated bamboo and the treated bamboo at $200{ }^{\circ} \mathrm{C}$ for 2,4 and $6 \mathrm{~h}$. An obvious high diffraction peak at $2 \theta=22.00^{\circ}$ corresponds to the (002) plane of cellulose crystal. The peak at $2 \theta=15.60^{\circ}$ corresponds to the (101) and (10-1) planes of cellulose [37]. The diffraction angle of (002) crystal plane, relative crystallinity and the lattice spacing of bamboo before and after treatment are shown in Table 3. It can be seen from Table 3 that the difference between diffraction angles of

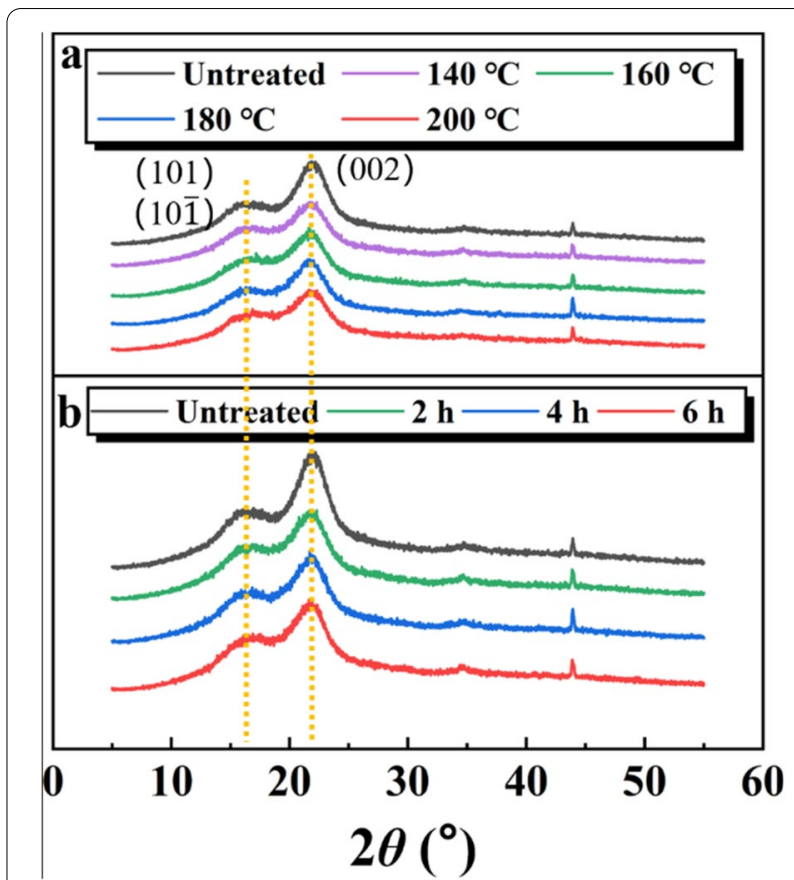

Fig. $3 \times R D$ spectra of untreated sample and the treated samples treated $\mathbf{a}$ at varied temperature $\left(140,160,180\right.$ and $\left.200{ }^{\circ} \mathrm{C}\right)$ for $6 \mathrm{~h}$ and b at $200^{\circ} \mathrm{C}$ for varied time $(2,4$ and $6 \mathrm{~h})$, respectively

oil-treated and untreated bamboo is very small. And, perhaps, the instrumental correction was not performed to cause the phenomenon. Meanwhile, compared with the untreated bamboo, the lattice spacing of the treated bamboo decreases. This is proved to be attributed to the formation of ether bonds among cellulose macromolecular chains [38].

The hydrolysis of the acetyl group in hemicellulose produces acetic acid when the heat treatment temperature is higher than $140{ }^{\circ} \mathrm{C}$. The latter has a catalysis effect on the hydrolysis of cellulose microfibril in the crystalline region. As a result, unstable glycoside bonds in

Table 3 The $2 \theta$, relative crystallinity and lattice spacing of untreated and oil heat-treated bamboo samples

\begin{tabular}{lllll}
\hline$T /{ }^{\circ} \mathrm{C}$ & t/h & $2 \theta{ }^{\circ}$ & $\begin{array}{l}\text { Relative } \\
\text { crystallinity } / \%\end{array}$ & $\begin{array}{l}\text { lattice } \\
\text { spacing / } \\
\mathrm{nm}\end{array}$ \\
\hline Untreated & & 21.84 & 43.12 & 4.07 \\
140 & 6 & 21.66 & 45.79 & 4.10 \\
160 & & 21.74 & 43.37 & 4.08 \\
180 & & 21.62 & 44.16 & 4.11 \\
200 & 2 & 21.66 & 45.55 & 4.10 \\
& 4 & 21.70 & 45.37 & 4.09 \\
& 6 & 21.70 & 44.28 & 4.09 \\
\hline
\end{tabular}


cellulose decompose, and the corresponding crystallinity decreases from $45.79 \%$ for $140{ }^{\circ} \mathrm{C}$ to $43.37 \%$ for $160{ }^{\circ} \mathrm{C}$ in Table 3. When treated at $180^{\circ} \mathrm{C}$ for $6 \mathrm{~h}$, the relative crystallinity of bamboo samples increases to $44.16 \%$. This may be because hemicellulose degradation promotes the arrangement of cellulose molecular chains in the amorphous region more orderly and closer [39]. When the heat temperature further increases from $180^{\circ} \mathrm{C}$ to $200{ }^{\circ} \mathrm{C}$, the crystallinity of cellulose basically remains unchanged with a value of $44.28 \%$, indicating an equilibrium balance between the hydrolysis processes of hemicellulose and the hydrolysis and rearrangement processes of cellulose in the amorphous region. As a result, the corresponding crystallinity is substantially retained.

\section{Effect of oil heat treatment on chemical functional groups of bamboo}

Figure 4 shows the FTIR spectra of untreated and oil heat-treated bamboo samples. Figure 4a shows the FTIR spectra of untreated and oil heat-treated bamboo samples at $200{ }^{\circ} \mathrm{C}$ for 2,4 and $6 \mathrm{~h}$. Figure $4 \mathrm{~b}$ shows the FTIR spectra of untreated and oil heat-treated bamboo at 140, 160, 180 and $200{ }^{\circ} \mathrm{C}$ for $6 \mathrm{~h}$. Table 4 shows the relative intensity of $400-4000 \mathrm{~cm}^{-1}$ absorption peak of moso bamboo before and after oil heat treatment. The peak at $1426 \mathrm{~cm}^{-1}$ is assigned to the $\mathrm{CH}_{2}$ bending deformation in cellulose. According to previous reports, this absorption band is assumed to be essentially unaltered by the heat treatment $[40,41]$. Thus, the peak intensity at $1426 \mathrm{~cm}^{-1}$ is set as 1 and used for spectrum normalization. The band at $3420 \mathrm{~cm}^{-1}$ is assigned to hydroxyl. The result shows that the intensity of absorption peak decreased after oil heat treatment. Under the combined action of oil heat and oxygen containing conditions, a large number of hydroxyl groups in the amorphous region of cellulose are oxidized. Free hydroxyl $(-\mathrm{OH})$ polymerizes to form aldehyde, ketone or carboxyl group. Therefore, cellulose degrades and the hydroxyl group decreases. The band at $2924 \mathrm{~cm}^{-1}$ has been associated with methyl groups $\mathrm{C}-\mathrm{H}$ bend. The displacement of $\mathrm{C}-\mathrm{H}$ band is an indication that cellulose structure was affected during oil heat treatment due to the degradation of cellulose in the cell wall of the bamboo. The band at $1732 \mathrm{~cm}^{-1}$ is assigned to the $\mathrm{C}=\mathrm{O}$ stretching vibrations in acetyl group present in hemicelluloses. The intensity of the band decreased significantly, mainly after oil heat treatments over $160{ }^{\circ} \mathrm{C}$. This is because the acetyl group in hemicellulose highly degrades by deacetylation reaction. The band at $1605 \mathrm{~cm}^{-1}$ is assigned to the $\mathrm{C}=\mathrm{O}$ and $\mathrm{C}=\mathrm{C}$ aromatic skeletal vibrations in lignin, which indicates that the heat treatment of the bamboo led to degradation of $\mathrm{C}=\mathrm{O}$ linked to the aromatic skeleton in lignin. The decrease in intensities of absorption band at $1515 \mathrm{~cm}^{-1}$ is not obvious, which indicates the benzene ring structure of lignin is relatively stable. Lignin can be esterified in acidic condition, resulting in the reduction of hydroxyl group [42]. The band at $1456 \mathrm{~cm}^{-1}$ is ascribed to $\mathrm{CH}_{2}$ symmetric bending on the xylan ring. The intensity is weakened, but not obvious. It is probable that no major degradation of the xylan backbone had occurred, and that the primary effect on the xylan is a side-group splitting [43]. The bands at $1243 \mathrm{~cm}^{-1}$ and $1161 \mathrm{~cm}^{-1}$ should be attributed to cellulose [44]. The two bands intensity and peak shape slightly changed after oil heat treatment. It may be the
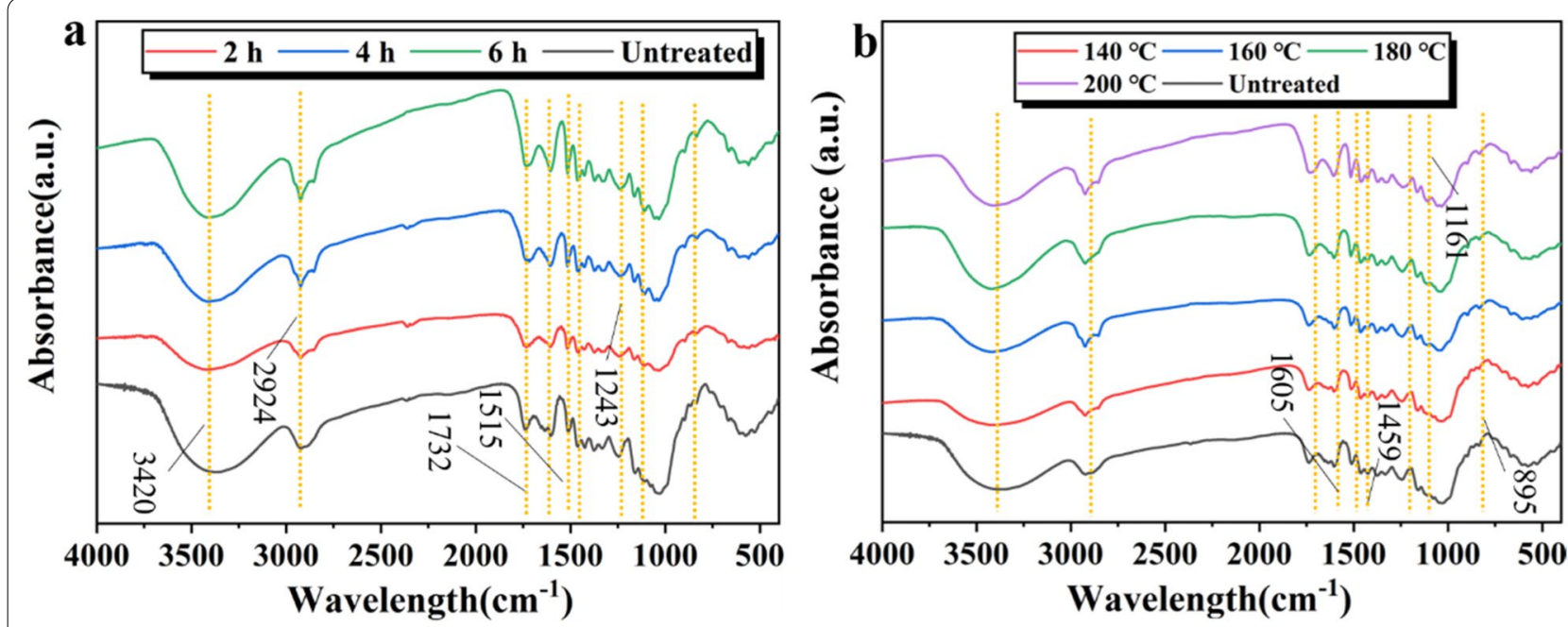

Fig. 4 FTIR spectra of untreated sample and the treated samples treated $\mathbf{a}$ at $200^{\circ} \mathrm{C}$ for varied time $(2,4$ and $6 \mathrm{~h})$ and $\mathbf{b}$ at varied temperature $(140$, 160,180 and $200^{\circ} \mathrm{C}$ ) for $6 \mathrm{~h}$, respectively 
Table 4 Relative intensity of absorption peak of untreated and oil heat-treated bamboo samples

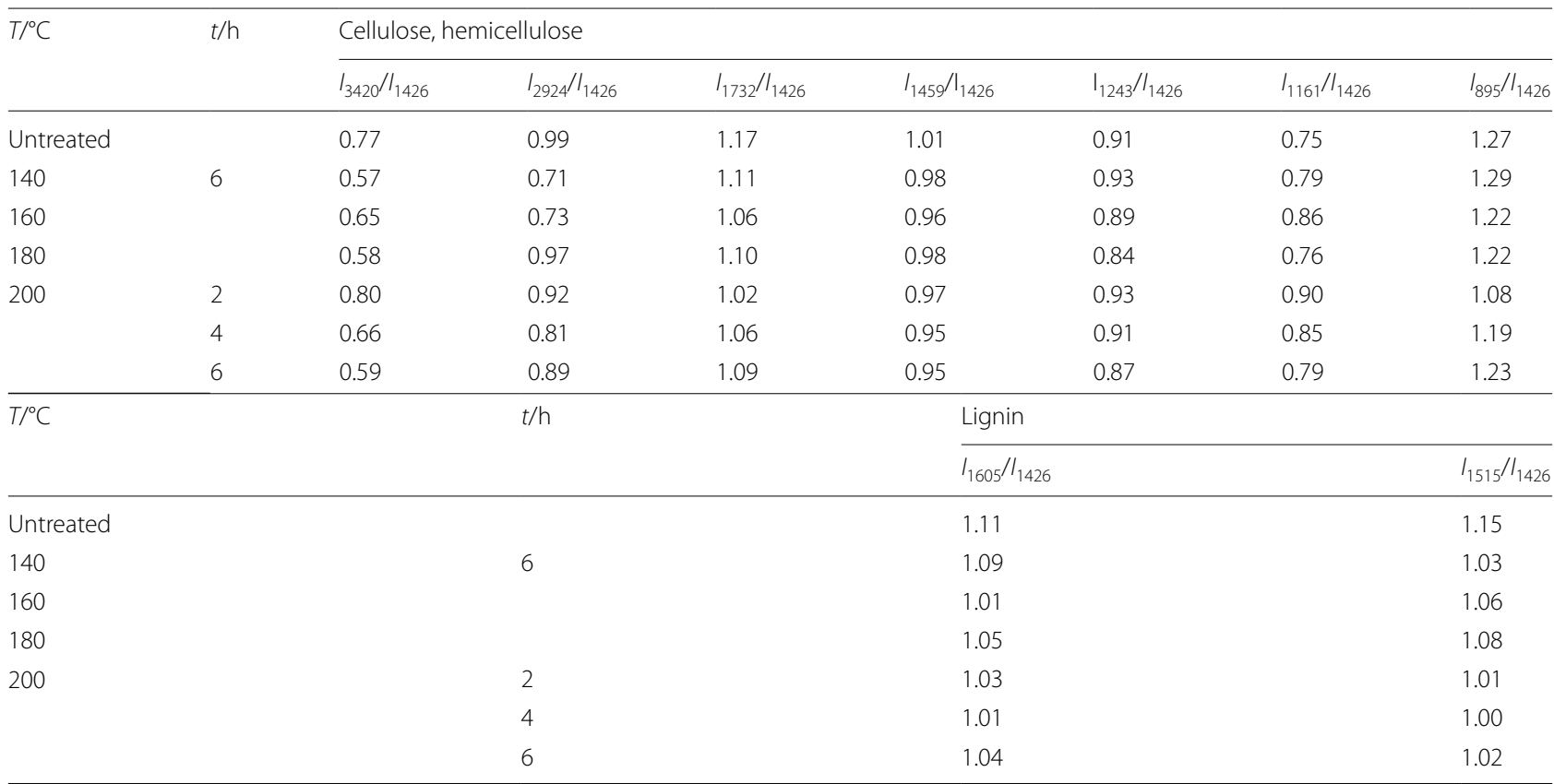

result of a reaction taking place between cellulose and the silicon oil during heat treatment. The decrease in intensities of absorption band at $895 \mathrm{~cm}^{-1}$ is due to the decrease in cellulose content.

\section{Effect of oil heat treatment on the cellulose, hemicellulose, and lignin contents}

The relative normalized contents of the cellulose, hemicellulose and lignin before and after oil heat treatment are shown in Fig. 5. It can be seen that the oil temperature has a significant effect on the content of cellulose, hemicellulose and lignin in bamboo. Compared with untreated samples, the contents of cellulose and hemicellulose in treated bamboo decrease. With the increase of heat treatment temperature, the contents of cellulose and hemicellulose decrease gradually. On the contrary, the relative content of lignin increases gradually. There is no obvious change in cellulose content of bamboo at $140{ }^{\circ} \mathrm{C}-160{ }^{\circ} \mathrm{C}$, which indicates the cellulose is almost no degraded. The content of hemicellulose decreases obviously at $160{ }^{\circ} \mathrm{C}$ for $6 \mathrm{~h}$, which indicates the hemicellulose begin to be degraded. The cellulose and hemicellulose contents of heat-treated samples at $180{ }^{\circ} \mathrm{C}$ for $6 \mathrm{~h}$ decrease by $36.6 \%$ and $37.2 \%$, respectively, compared to the control group. The decline rate of cellulose and hemicellulose content are $43.99 \%$ and $60.56 \%$, respectively, when the bamboo is
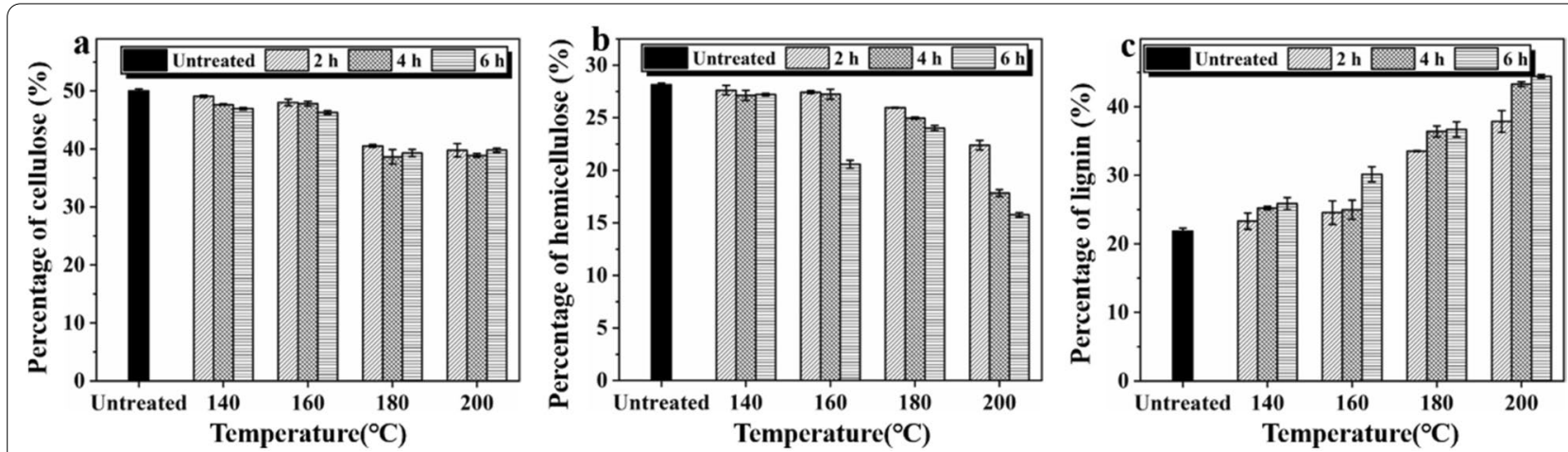

Fig. 5 The percentage of cellulose, hemicellulose and lignin of untreated sample and the treated samples at varied temperature $(140,160,180$ and $\left.200^{\circ} \mathrm{C}\right)$ for varied time $(2,4$ and $6 \mathrm{~h})$. a Cellulose, $\mathbf{b}$ hemicellulose, $\mathbf{c}$ lignin 
oil heat treated at $200{ }^{\circ} \mathrm{C}$ for $6 \mathrm{~h}$. At this time, the contents of cellulose and hemicellulose have no significant decrease. The decrease of cellulose content is mainly due to the volatilization of small molecular degradation products during oil heat treatment. The decrease of hemicellulose content is mainly due to its poor thermal stability and easy hydrolysis. The hydrolysis of the acetyl group in hemicellulose produces acetic acid when the heat treatment temperature is higher than $140{ }^{\circ} \mathrm{C}$, which leads to acid-catalyzed degradation of polysaccharide [39]. Furthermore, the hydrolysis of the acetyl group in hemicellulose produces acetic acid when the heat treatment temperature is higher than $140{ }^{\circ} \mathrm{C}$. The latter has a catalysis effect on the hydrolysis of cellulose microfibril in the crystalline region. As a result, unstable glycoside bonds in cellulose decompose, and the corresponding crystallinity of cellulose decreases from $45.79 \%$ for $140{ }^{\circ} \mathrm{C}$ to $43.37 \%$ for $160{ }^{\circ} \mathrm{C}$ in Table 3 . The acetic acid produced by hemicellulose degradation catalyzes the degradation of cellulose, as a result of which, the content of cellulose decreases. The cellulose and hemicellulose are polysaccharides and the structure of polysaccharide is unstable during high-temperature heat treatment because of their branched chain and amorphous structure. Therefore, the cellulose and hemicellulose are easier to hydrolysis at high temperature than other components $[45,46]$. With the decrease of cellulose and hemicellulose contents, the relative content of lignin increases due to its good thermal stability.

\section{Effect of oil heat treatment on the surface wettability of bamboo}

Figure 6 shows the contact angle of the outer layer of bamboo surface before and after heat treatment. It can be seen that the contact angle of untreated outer layer of bamboo samples surface is $58.03^{\circ}$ and that of oil heat-treated samples are $87.2 \pm 2.3^{\circ}$. The contact angle of oil heat-treated bamboo is much larger than that of untreated bamboo. It is mainly because the anhydride functional groups in the oil can combine with the hydroxyl group of hemicellulose through hydrogen bonding or ester bonding reactions during oil heat treatment. As a result, the remained heating medium (oil) on the surface of outer layer improves the hydrophobic properties of the surface [47]. In addition, the waxes in the oil heat-treated bamboo are likely to transfer to the surface, forming a waterproofing membrane and thus increasing the hydrophobicity of bamboo [15]. The obtained membrane can be confirmed by AFM imaging as shown in Additional file 1: Figure S1. An obvious difference can be observed between the treated and untreated sample surface from the AFM image in Figure S1a. This height difference is mainly due to the formation of oil membrane

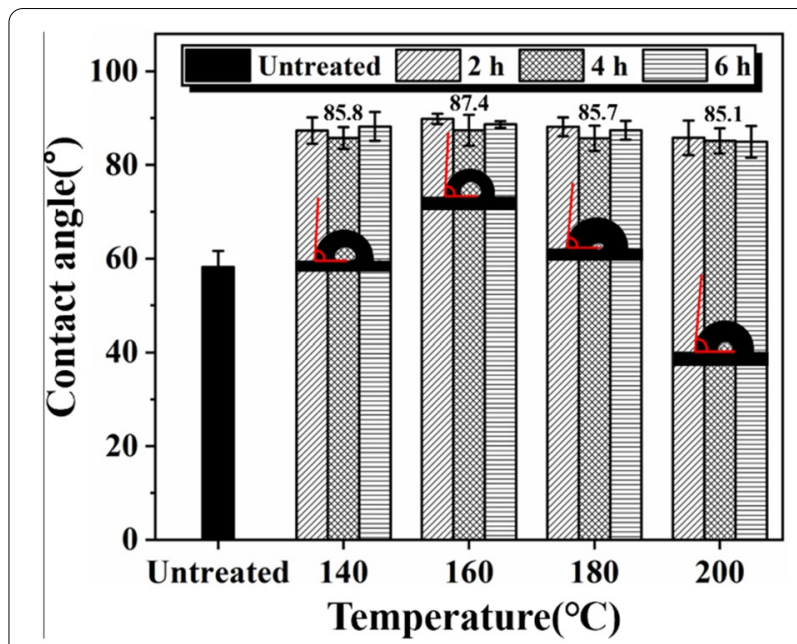

Fig.6 The contact angle of untreated sample and the treated samples at varied temperature $\left(140,160,180\right.$ and $\left.200^{\circ} \mathrm{C}\right)$ for varied time $(2,4$ and 6 h)

layer on the bamboo surface with a thickness of $\sim 350 \mathrm{~nm}$ (Additional file 1: Figure S1b). Furthermore, as observed in Fig. $2 \mathrm{~d}$ that the pits are blocked by the mixture of oil molecules and starch degradation products, the entry of external water is inhibited to a certain extent. The retained oil on the surface of bamboo is hydrophobic and has a negative effect on the wettability [48].

\section{Effect of oil heat treatment on physical and mechanical properties of bamboo}

The compressive strength parallel to grain of bamboo samples before and after oil heat treatment at different times and temperatures is shown in Fig. 7. As can be seen from Fig. 7, the compressive strength parallel to grain of the untreated samples is $89.07 \mathrm{MPa}$. With the increase of oil heat treatment temperature, the compressive strength parallel to grain increases first and then decreases. Under the condition of oil heat treatment at $160^{\circ} \mathrm{C}$ for $2 \mathrm{~h}$, the compressive strength parallel to grain of samples reaches the maximum of $109.52 \mathrm{MPa}$. The maximum is $18.63 \%$ higher than that of untreated samples, and then begins to decline. When the temperatures are up to $200{ }^{\circ} \mathrm{C}$, the compressive strength parallel to grain of the oil heattreated samples is less than that of the untreated samples. As we know, the cellulose and lignin endow bamboo with elasticity and strength, hardness and rigidity, respectively, and the increase of cellulose and lignin in the cell wall has a positive effect on the compressive strength parallel to grain of bamboo [49]. The increase of compressive strength parallel to grain may be due to the increased crosslinking of lignin polymer during the heat treatment [28]. Lignin is used as a reinforcing agent for cellulose 


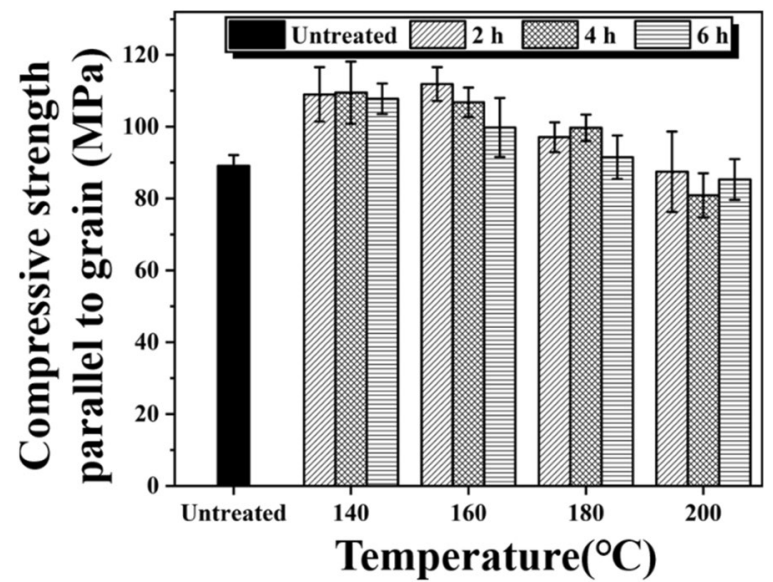

Fig. 7 The compressive strength parallel to grain of untreated sample and the treated samples at varied temperature $(140,160,180$ and $\left.200{ }^{\circ} \mathrm{C}\right)$ for varied time $(2,4$ and $6 \mathrm{~h})$

microfiber/fibril, and the increase in crosslinking of this polymer may prevent or limit movement perpendicular to the particle. In addition, lignin is the main component of the interlayer, and the crosslinking of lignin polymer enhances the strength of the intermediate layer and affects the strength nature of cell wall [50]. Similar to wood, the decrease of compressive strength parallel to grain is mainly due to the pectin, extract, hemicellulose and other substances in bamboo are degraded partially or completely, especially when the temperature is higher than $160{ }^{\circ} \mathrm{C}$ [51].

The bending strength and the modulus of elasticity (MOE) of bamboo samples before and after oil heat treatment are shown in Fig. 8. As shown in Fig. 8, when the oil heat treatment temperature is less than $140{ }^{\circ} \mathrm{C}$, the bending strength decreases with the increase of the heat treatment time. When the oil heat-treated temperature is higher than $140{ }^{\circ} \mathrm{C}$, the bending strength increases first and then decreases. The bending strength of the bamboo samples increase by $8.46 \%, 19.26 \%$ and $17.25 \%$, respectively, after oil heat treatment at 160,180 and $200{ }^{\circ} \mathrm{C}$ for $2 \mathrm{~h}$. At the beginning of oil heat treatment, the moisture content at the fiber saturation point decreases, and the dimensional stability improves, resulting in the increase of the bending strength $[52,53]$. At the same temperature, the bending strength decreases with the time increasing, and it is mainly due to the degradation of chemical components including cellulose and hemicellulose. From Fig. 8, the MOE of oil heat-treated samples is higher than control group, which shows that the oil heat-treated bamboo has higher strength and better dimensional stability (MOE is positively correlated with dimensional stability [26]). And the MOE is better dimensional stability. The results are consistent with the results of bamboo dry shrinkage (Table 5). With the increase of oil temperature and time, the dry shrinkage decreases gradually. This may be due to the loss of water absorption sites and the decrease in the number of $\mathrm{O}-\mathrm{H}$ and $\mathrm{C}=\mathrm{O}$ groups [54]. This is coincident with the result of FTIR spectra (Fig. 4). Furthermore, with the increase of temperature, the modulus of elastic increases first and then decreases. The modulus of elastic reaches the maximum $12,373 \mathrm{MPa}$ at $180{ }^{\circ} \mathrm{C}$ for $2 \mathrm{~h}$ and increases by $59.04 \%$ compared with untreated samples. The loss of moisture in the amorphous area of cellulose leads to the fact that the cellulose molecules firmly bind to each
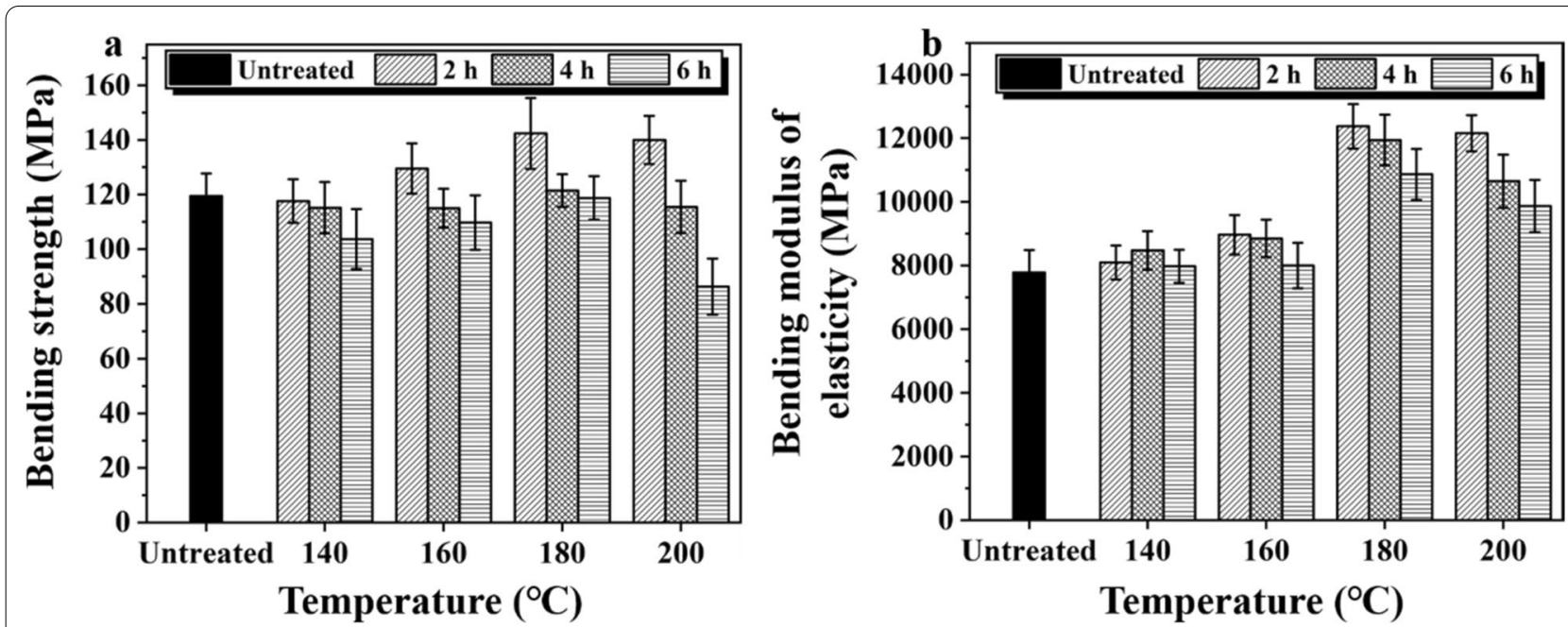

Fig. 8 The bending strength and the MOE of untreated sample and the treated samples at varied temperature $\left(140,160,180\right.$ and $\left.200{ }^{\circ} \mathrm{C}\right)$ for varied time $(2,4$ and 6 h) 
Table 5 The dry shrinkage and weight loss of untreated and oil heat-treated bamboo samples

\begin{tabular}{|c|c|c|c|c|c|c|c|c|}
\hline \multirow[t]{2}{*}{$T /{ }^{\circ} \mathrm{C}$} & \multirow[t]{2}{*}{$t / h$} & \multicolumn{3}{|c|}{ Oven-dried shrinkage/\% } & \multicolumn{3}{|c|}{ Air-dried shrinkage /\% } & \multirow[t]{2}{*}{ Weight loss/\% } \\
\hline & & Radial & Tangential & Volume & Radial & Tangential & Volume & \\
\hline \multicolumn{2}{|l|}{ Untreated } & 4.22 & 5.42 & 9.68 & 3.74 & 5.30 & 9.68 & - \\
\hline \multirow[t]{3}{*}{140} & 2 & 4.16 & 5.39 & 9.36 & 3.44 & 5.17 & 9.36 & 2.56 \\
\hline & 4 & 4.17 & 5.45 & 11.04 & 3.34 & 4.32 & 7.38 & 3.76 \\
\hline & 6 & 4.16 & 5.27 & 8.55 & 3.14 & 3.89 & 7.26 & 3.81 \\
\hline \multirow[t]{3}{*}{160} & 2 & 3.75 & 5.42 & 9.47 & 3.42 & 4.22 & 8.34 & 3.73 \\
\hline & 4 & 4.03 & 5.31 & 9.27 & 3.23 & 4.11 & 6.94 & 3.92 \\
\hline & 6 & 4.01 & 5.02 & 8.96 & 3.02 & 3.54 & 6.57 & 3.89 \\
\hline \multirow[t]{3}{*}{180} & 2 & 3.39 & 4.66 & 8.36 & 3.32 & 3.34 & 6.71 & 8.60 \\
\hline & 4 & 3.15 & 4.35 & 7.43 & 2.64 & 3.47 & 6.55 & 8.35 \\
\hline & 6 & 3.09 & 2.22 & 5.43 & 2.16 & 1.97 & 4.48 & 8.50 \\
\hline \multirow[t]{3}{*}{200} & 2 & 1.66 & 1.86 & 2.75 & 1.76 & 2.21 & 3.52 & 14.91 \\
\hline & 4 & 1.60 & 1.49 & 4.21 & 1.61 & 2.57 & 5.04 & 18.14 \\
\hline & 6 & 0.74 & 1.44 & 2.37 & 1.55 & 1.90 & 3.95 & 18.64 \\
\hline
\end{tabular}

other, which increases the rigidity of the fiber and the modulus of elasticity [55]. The increase in modulus of elasticity also confirms that the high temperature has a positive effect on the plasticity. Previous studies have suggested that the amorphous cellulose is partially crystallized, which increases the hardness of bamboo $[45,56]$. Abundant hemicellulose is decomposed with the time, and the degradation of cellulose reduces cellulose polymerization degree and destroys the hydrogen bond, resulting in the gradual decrease in the mechanical strength. Besides, from Table 5 we can see that the weight loss of the treated samples increases with the increase of temperature. This is supposed to be attributed to the varied degradation behavior of the different chemical components in bamboo at different temperatures as discussed above.

\section{Effect of oil heat treatment on the decay resistance of bamboo}

Bamboo-based products are easy to decay when used outdoors, which affects their beauty and durability. Therefore, we study the decay resistance of bamboo after oil heat treatment. It is reported that brown-rot fungi are one of the most common rot fungi that can easily infect bamboo [57]. In view of this, we studied the decay behavior of the treated bamboo by brown-rot fungi. Figure 9 shows the weight loss of bamboo samples before and after oil heat treatment after incubation with brown-rot fungi for 45 days. As we know, the more weight loss means the worse decay resistance. From Fig. 9, it can be concluded that the weight loss of bamboo samples is between 0 and $20 \%$ after being infected by brown-rot fungi for 45 days. According to Table 1, the corresponding decay resistance

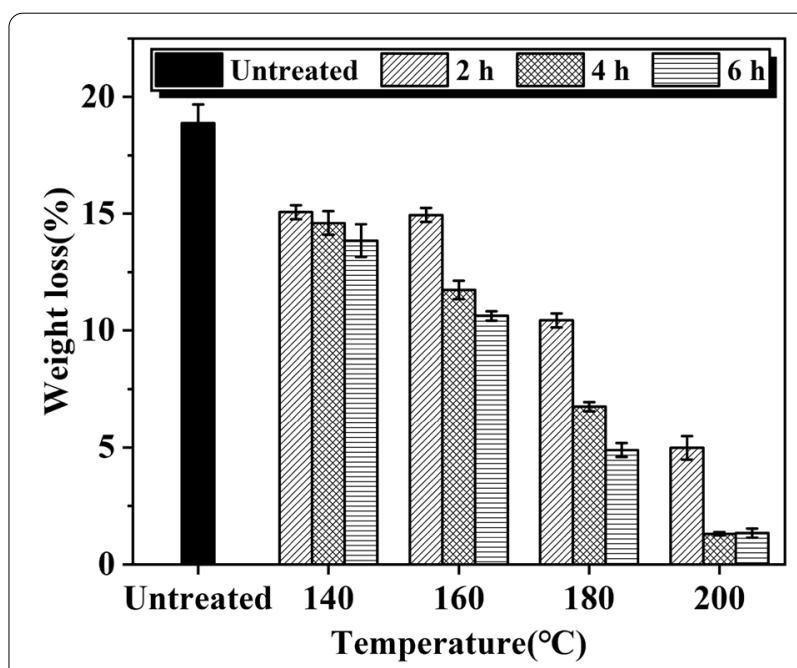

Fig. 9 The weight loss of samples after incubation with brown-rot fungi for 45 days

grade of the treated samples is I or II. With the increase of oil heat treatment temperature and time, the weight loss rate caused by brown-rot fungi infection decreases. When the temperature is higher than $180{ }^{\circ} \mathrm{C}$, the decay resistance grade reaches $\mathrm{I}$, the best decay resistance. The results show that the decay resistance of bamboo samples becomes better with the increase of oil heat-treated temperature and time. And with the increase of the temperature and time, the effect of decay resistance is better. This is because the pit is blocked (Fig. 2), which prevents the invasion of water and decay fungi. To a certain extent, the decay resistance of bamboo is improved [58]. Another reason is that brown-rot fungi mainly degrade cellulose 
and hemicellulose in bamboo. However, cellulose and hemicellulose degrade under the high-temperature condition, resulting in the reduction of the infection by brown-rot fungi.

\section{Effect of oil heat treatment on the anti-mildew property of bamboo}

Figure 10 shows the infection ratio of bamboo samples. Figure $10 \mathrm{a}-\mathrm{d}$ are the bamboo samples infected by three mixed fungi under oil heat treatment at 140 , 160,180 and $200{ }^{\circ} \mathrm{C}$, respectively. Three kinds of mold are Aspergillus niger, Penicillium citrinum and Trichoderma viride. Table 6 shows the mold control efficiency of the treated bamboo samples. Figure 11 shows the starch content of bamboo samples before and after treatment. It can be seen from Fig. 10 that the infection ratio of samples after oil heat treatment is lower than that of control group obviously. The untreated
Table 6 The mold control efficiency of oil heat-treated bamboo samples

\begin{tabular}{llll}
\hline Treatment & \multicolumn{3}{l}{ Mold control efficiency/\% } \\
\cline { 2 - 4 } & $2 \mathrm{~h}$ & $4 \mathrm{~h}$ & $6 \mathrm{~h}$ \\
\hline $140^{\circ} \mathrm{C}$ & 12.33 & 12.35 & 16.70 \\
$160^{\circ} \mathrm{C}$ & 13.06 & 51.55 & 31.87 \\
$180^{\circ} \mathrm{C}$ & 20.14 & 48.53 & 51.55 \\
$200^{\circ} \mathrm{C}$ & 65.70 & 82.81 & 92.03 \\
\hline
\end{tabular}

samples are infected on the second day, and the ratio infection reaches $100 \%$ on the 6 th day. The mold control efficiency of oil heat treatment at $140{ }^{\circ} \mathrm{C}$ for 2,4 and $6 \mathrm{~h}$ are $12.33 \%, 12.35 \%$ and $16.70 \%$, respectively. The infection of the samples starts on the fourth day. And the infection ratio of samples reaches $100 \%$ more
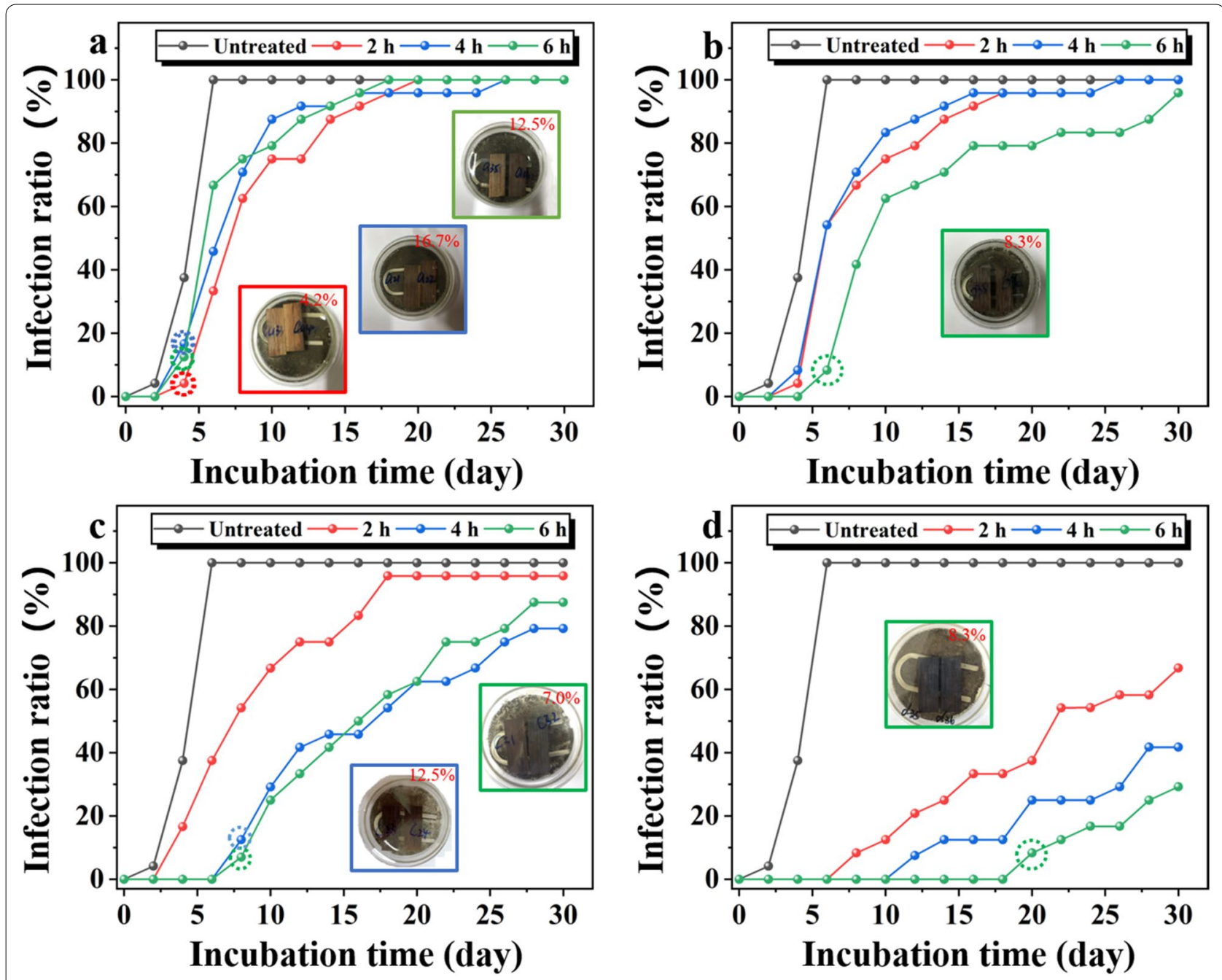

Fig. 10 The infection ratio of untreated and oil heat-treated samples with three mixed fungi: a $140{ }^{\circ} \mathrm{C}, \mathbf{b} 160^{\circ} \mathrm{C}, \mathbf{c} 180^{\circ} \mathrm{C}, \mathbf{d} 200^{\circ} \mathrm{C}$ 


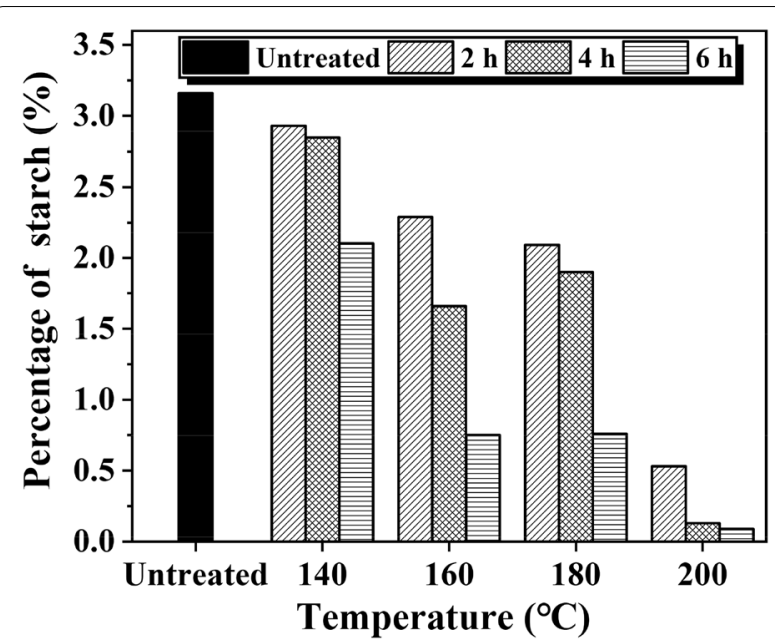

Fig. 11 The starch content of untreated and oil heat-treated samples at varied temperature $\left(140,160,180\right.$ and $\left.200{ }^{\circ} \mathrm{C}\right)$ for varied time $(2,4$ and 6 h)

than 16 days (Additional file 1: Figure S2). Under the condition, it has a certain effect of anti-mildew, but not effective. When the temperature is higher than $160{ }^{\circ} \mathrm{C}$, the average control effect increases significantly. And when the temperature is constant, the day that bamboo begins to be infected is delayed with the increase of treatment time. The mold control efficiency is obviously improved. When the temperature is higher than $180{ }^{\circ} \mathrm{C}$, the infection ratio did not reach $100 \%$ after 30 days, and the infection value of mold growth on bamboo is 1. Furthermore, it can be seen obviously from Additional file 1: Figure S2 that with the increase of treatment time, the infection ratio of bamboo samples decreases. After heat treatment at $200{ }^{\circ} \mathrm{C}$ for $6 \mathrm{~h}$, the samples begin to be infected on the 20th day, and only a few hyphae are found on the surface after 30 days. The anti-mildew effect is best, the infection ratio is only $29 \%$, and the mold control efficiency of samples is $92 \%$.

Generally speaking, mold growth requires appropriate temperature, humidity, oxygen and nutrients. From the inherent characteristics of materials, chemical components play an important role in mold growth on wood, bamboo and other wood fiber materials, especially the sugar and starch with high content [43]. According to Fig. 11, the starch content decreases with the increase of oil heat treatment temperature and time. And the hemicellulose content shows a decreasing trend (Fig. 5b). Both results indicate that the decrease of the contents of hemicellulose, moisture and starch inside the treated samples restrains mold growth. In addition, due to the blockage of pits (Fig. 2c) and the formation of oil film on the surface of the treated bamboo, mold is also effectively prevented from entering the interior of the samples. Consequently, the anti-mildew property of the bamboo is improved.

\section{Conclusions}

In this work, bamboo was heated with methyl silicone oil. The effect of treatment temperature $\left(140{ }^{\circ} \mathrm{C}-200^{\circ} \mathrm{C}\right)$ and time $(2 \mathrm{~h}-6 \mathrm{~h})$ on bamboo properties was studied systematically, including chemical composition, physical and mechanical properties, surface wettability, decay resistance and anti-mildew property. The goal is to provide comprehensive process parameters and micro-mechanism for the performance of oil heat treatment of bamboo, which can be used to guide the actual production.

After oil heat treatment at $200{ }^{\circ} \mathrm{C}$ for $6 \mathrm{~h}$, no starch granules remain inside the parenchymal cell lumen, which occurs obviously due to distortions and deformations. And the pits are blocked by the mixtures formed by starch and oil condensations.

As a result of oil heat treatment, the lattice spacing of cellulose crystal region increases and the obtained relative crystallinity of treated bamboo is higher than that of untreated bamboo.

With the increase of heat treatment temperature and time, the content of cellulose and hemicellulose decreases gradually while relative content of lignin increases due to its better thermal stability. Accordingly, the surface wettability decreases due to the changes of the surface functional groups and micro-morphologies.

The compressive strength parallel to grain of treated bamboo samples reaches the maximum value of 109.52 $\mathrm{MPa}$ at $160{ }^{\circ} \mathrm{C}$ for $2 \mathrm{~h}$.

The maximal resulted bending strength and MOE values are obtained after oil heat treatment at $180{ }^{\circ} \mathrm{C}$ for $2 \mathrm{~h}$, which are 142.42 $\mathrm{MPa}$ and 12,373.00 $\mathrm{MPa}$, respectively.

The decay resistance and anti-mildew property of bamboo are dramatically enhanced with increased heat treatment temperature and time. This is mainly attributed to the blocking of internal channels for nutrient exchange, the decrease of surface wettability induced by the change of surface functional groups, and the degradation of polysaccharides and starch after oil heat treatment.

\section{Abbreviations \\ SEM: Scanning electron microscopy; AFM: Atomic force microscopy; XRD: X-ray diffraction; FTIR: Fourier transform infrared spectroscopy; MOE: Modulus of elasticity.}

\section{Supplementary Information}

The online version contains supplementary material available at https://doi. org/10.1186/s10086-021-01959-7. 
Additional file 1: Figure S1. (a) AFM images of the interface between the untreated (left) and treated (right) bamboo surface. (b) Corresponding cross-sectional profile for the green dashed line. Figure $\mathbf{S 2}$. Pictures of untreated sample (a) and the treated samples treated (b1-b3) at $140{ }^{\circ} \mathrm{C}$ for varied time ( $2 \mathrm{~h}, 4 \mathrm{~h}$ and $6 \mathrm{~h}),(\mathbf{c 1}-\mathrm{c} 3)$ at $160^{\circ} \mathrm{C}$ for varied time $(2 \mathrm{~h}, 4 \mathrm{~h}$ and $6 \mathrm{~h}),(\mathbf{d} \mathbf{1}-\mathbf{d} \mathbf{3})$ at $180^{\circ} \mathrm{C}$ for varied time and (e1-e3) at $200^{\circ} \mathrm{C}$ for varied time ( $2 \mathrm{~h}, 4 \mathrm{~h}$ and $6 \mathrm{~h}),(2 \mathrm{~h}, 4 \mathrm{~h}$ and $6 \mathrm{~h})$, respectively.

\section{Acknowledgements}

The authors would like to thank Forestry Bureau of Zixi County in China for providing the untreated bamboo as raw materials.

\section{Authors' contributions}

$\mathrm{XMH}$ and $\mathrm{QYW}$ analyzed and interpreted the obtained results. $\mathrm{XMH}, \mathrm{XH}$ and CLY performed the SEM, XRD, FTIR and HPLC characterizations. YHW and YC performed the oil heat treatment experiments and the biological antibacterial tests. XMH and $\mathrm{ZCL}$ are major contributors in writing the manuscript. And YJL designed the experiments and helped to analyze the data. All authors read and approved the final manuscript.

\section{Funding}

This research was funded by Financial support from the National Natural Science Foundation of China (No. 31971740), China Postdoctoral Science Foundation (2017M621598), Nature Science Foundation of Jiangsu Province (BK20160939), Key University Science Research Project of Jiangsu Province (17KJA220004), Jiangsu Agricultural Science and Technology Independent Innovation Fund (CX(20)3041), Science and Technology Program of Fujian Province (2019N3014), Open Fund of Key Laboratory of National Forestry and Grassland Administration/Beijing for Bamboo \& Rattan Science and Technology (ICBR-2020-08).

\section{Availability of data and materials}

All data generated or analyzed during this study are included in this published article and its Additional file 1.

\section{Declarations}

\section{Competing interests}

The authors declare that they have no competing interests.

\section{Author details}

1 Jiangsu Co-Innovation Center of Efficient Processing and Utilization of Forest Resources, College of Materials Science and Engineering, Nanjing Forestry University, Nanjing 210037, China. ${ }^{2}$ Key Laboratory of National Forestry and Grassland Administration/Beijing for Bamboo \& Rattan Science and Technology, Beijing 100102, China. ${ }^{3}$ Forestry Bureau of Zixi County, Fuzhou 335300, Jiangxi, China.

Received: 1 November 2020 Accepted: 17 March 2021

Published online: 25 March 2021

\section{References}

1. Abdul Khalil HPS, Bhat IUH, Jawaid M, Zaidon A, Hermawan D, Hadi YS (2012) Bamboo fibre reinforced biocomposites: a review. Mater Des 42:353-368

2. Li YJ, Xu B, Zhang QS, Jiang SX (2016) Present situation and the countermeasure analysis of bamboo timber processing industry in China. J For Eng 1(1):2-7

3. Tausif M, Ahmad F, Hussain U, Abdul B, Tanveer H (2015) A comparative study of mechanical and comfort properties of bamboo viscose as an eco-friendly alternative to conventional cotton fibre in polyester blended knitted fabrics. J Clean Prod 89:110-115

4. Prakash C, Ramakrishnan G (2013) Effect of blend proportion on thermal behaviour of bamboo knitted fabrics. J Text Inst 104:907-913

5. Yu Y, Zhu R, Wu B, Hu Y, Yu W (2015) Fabrication, material properties, and application of bamboo scrimber. Wood Sci Technol 49:83-98
6. Lou ZC, Yuan TC, Wang QY, Wu XW, Hu SH, Hao XM, Liu XM, Li YJ (2021) Fabrication of crack-free flattened bamboo and its macro-/micro- morphological and mechanical properties. J Renew Mater 9(5):959-977

7. Zhong LL, Wei CY, Xiao Y, Shan B (2012) The regional expression in utilization of material construction: the landscape sketch practice of the modern bamboo structures in Meixi Lake project. Key Eng Mater 517:150-157

8. Zhang YH, Huang YX, Yu WJ, Ma H (2019) Development, current situation and trend of bamboo industry in China. Wood-Based Panel 6:32-32

9. Depuydt DE, Sweygers N, Appels L, Ivens J, Vuure AW (2019) Bamboo fibres sourced from three global locations: a microstructural, mechanical and chemical composition study. J Reinf Plast Compos 38:397-412

10. Yu Y, Huang X, Yu W (2014) A novel process to improve yield and mechanical performance of bamboo fiber reinforced composite via mechanical treatments. Compos B Eng 56:48-53

11. Sun FB, Jiang ZH, Fei BH, Yu ZX, Wang H (2011) Effect of $Y$-Ray application on bamboo mold resistance. China Wood Ind 25:23-25

12. Liu G, Lu Z, Zhu X, Du X, Hu J, Chang S (2019) Facile in-situ growth of Ag/ $\mathrm{TiO}_{2}$ nanoparticles on polydopamine modified bamboo with excellent mildew-proofing. Sci Rep 9:16496

13. Sun FL, Duan XF, Wen GF, Mao SF (2006) Anti-mold effects of CMC wood preservatives on bamboo wood. Sci Silvae Sinicae 3(3):40-43

14. Sun F, Bao B, Ma L (2012) Mould-resistance of bamboo treated with the compound of chitosan-copper complex and organic fungicides. J Wood Sci 58:51-56

15. Lee CH, Yang TH, Cheng YW, Lee CJ (2018) Effects of thermal modification on the surface and chemical properties of moso bamboo. Constr Build Mater 178:59-71

16. Yang $\mathrm{TH}$, Lee CH, Lee CJ, Cheng YW (2016) Effect of different thermal modification media on physical and mechanical properties of moso bamboo. Constr Build Mater 119:251-259

17. Sun FB, Fei BH, Jiang ZH, Yu ZX, Tian GL, Yang QW (2011) Study on bamboo treated with $\gamma$ rays by $X$-ray diffraction. Spectrosc Spect Anal 31(06):1717-1719

18. Li JP, Wu ZX, Ren DJ, Chen YH (2019) Research progress on antifungal activities of inorganic nanomaterials in bamboo/wood. J Bamboo Sci 38(02):16-23

19. Peng WX, Wu FJ, Xue Q, Lin Z (2012) Study on synergy mold preservation to bamboo with extractives. AMR 496:367-369

20. Wang $X$, Cheng D, Huang $X$ et al (2020) Effect of high-temperature saturated steam treatment on the physical, chemical, and mechanical properties of moso bamboo. J Wood Sci 66:52

21. Tjeerdsma BF, Militz H (2005) Chemical changes in hydrothermal treated wood: FTIR analysis of combined hydrothermal and dry heat-treated wood. Holz Roh Werkst 63:102-111

22. Lou ZC, Yang LT, Zhang AW, Shen D, Liu J, Yang L, Li Y (2020) Influence of saturated steam heat treatment on the bamboo color. J For Eng 5(4):38-44

23. Leppänen $K$, Spetz P, Pranovich A (2011) Pressurized hot water extraction of Norway spruce hemicelluloses using a flow-through system. Wood Sci Technol 45:223-236

24. Hosseinaei O, Wang S, Rials TG (2011) Effects of decreasing carbohydrate content on properties of wood strands. Cellulose 18:841-850

25. Zhao R, Jiang Z, Hse C, Shupe T (2010) Effection of steam treatment on bending property and chemical composition of moso bamboo (Phyllostachyspubescens). J Trop For Sci 22:197-201

26. Zhang YM, Yu YL, Yu WJ (2013) Effect of thermal treatment on the physical and mechanical properties of Phyllostachyspubescens bamboo. Eur J Wood Prod 71:61-67

27. Song L, Ren H, Wang X, Ma J, Li C, Li Y, Xu B (2018) Effect of high temperature saturated steam treatment on bamboo properties. J For Eng 3(2):23-28

28. Tang T, Chen X, Zhang B, Liu X, Fei B (2019) Research on the physicomechanical properties of moso bamboo with thermal treatment in tung oil and its influencing factors. Materials 12:599

29. Lee SH, Ashaari Z, Lum WC, Halip JA, Ang AF, Tan LP, Chin KL, Tahir PM (2018) Thermal treatment of wood using vegetable oils: a review. Constr Build Mater 181:408-419

30. Dubey MK, Pang S, Walker J (2011) Effect of oil heating age on colour and dimensional stability of heat treated Pinusradiata. Eur J Wood Prod 69:255-262 
31. Okon KE, Udoakpan UI (2019) Physicochemical properties of Pinusmassoniana wood subjected to silicone oil heat treatment. Maderas Cienc Tecnol 21:531-544

32. Yuan ZR, Wu XW, Wang XZ, Zhang X (2020) Effects of one-step hot oil treatment on the physical, mechanical, and surface properties of bamboo scrimber. Molecules 25:4488

33. Huang CX, Lin WQ, Lai CH, Li X, Jin YC, Yong Q (2019) Coupling the postextraction process to remove residual lignin and alter the recalcitrant structures for improving the enzymatic digestibility of acid pretreated bamboo residues. Bioresour Technol 285:121355

34. GB/T 15780-1995 (1995) Testing methods for physical and mechanical properties of bamboos. GB Standards, China

35. ASTM D1413-99 (1999) Standard test method for wood preservatives by laboratory soil-block cultures. ASTM standards, West Conshohocken, PA

36. GB/T 18261-2013 (2013) Test method for anti-mildew agents in controlling wood mould and stain fungi. GB Standards, China

37. Cave ID (1997) Theory of X-ray measurement of microfibril angle in wood Wood Sci Technol 31:143-152

38. Lou Z, Yuan C, Li Y, Shen D, Yang L, Liu J, Zhang A (2020) Effect of saturated steam treatment on the chemical composition and crystallinity properties of bamboo bundles. J For Eng 5(2):29-35

39. Tang T, Zhang B, Liu X, Wang W, Chen X, Fei B (2019) Synergistic effects of tung oil and heat treatment on physicochemical properties of bamboo materials. Sci Rep 9:12824

40. Xiang E, Feng SH, Yang SM, Huang RF (2020) Sandwich compression of wood: effect of superheated steam treatment on sandwich compression fixation and its mechanisms. Wood Sci Technol 54(6):1529-1549

41. Yang $H$, Yan $R$, Chen $H$, Lee DH, Zheng C (2007) Characteristics of hemicellulose, cellulose and lignin pyrolysis. Fuel 86(12):1781-1788

42. Sun RH, Li XJ, Liu Y, Hou RG, Qiao JZ (2013) Effects of high temperature heat treatment on FTIR and XRD characteristics of bamboo bundles. $J$ Central South Univ For Sci Technol 33:97-100

43. Guo J, Song K, Salmén L, Yin Y (2015) Changes of wood cell walls in response to hygro-mechanical steam treatment. Carbohydr Polym 115:207-214

44. Cheng D, LiT, Smith GD, Xu B, LiY (2018) The properties of moso bamboo heat-treated with silicon oil. Eur J Wood Prod 76:1273-1278

45. Windeisen E, Strobel C, Wegener G (2007) Chemical changes during the production of thermo-treated beech wood. Wood Sci Technol 41:523-536

46. Qi HC, Cheng WL, Liu YX (2005) Mechanical characteristics and chemical compositions of superheated steam-treated wood under high temperature and pressure. J Nor For Univ 33(3):44-46
47. Wang X, Chen X, Xie X, Wu Y, Zhao L, Li Y, Wang S (2018) Effects of thermal modification on the physical, chemical and micromechanical properties of Masson pine wood (Pinusmassoniana Lamb.). Holzforschung 72:1063-1070

48. Li T, Cheng D, Wålinder MEP, Zhou D (2015) Wettability of oil heat-treated bamboo and bonding strength of laminated bamboo board. Ind Crops Prod 69:15-20

49. Okon KE, Lin F, Chen Y, Huang B (2017) Effect of silicone oil heat treatment on the chemical composition, cellulose crystalline structure and contact angle of Chinese parasol wood. Carbohydr Polym 164:179-185

50. Boonstra MJ, Acker J, Tjeerdsma BF, Kegel EV (2007) Strength properties of thermally modified softwoods and its relation to polymeric structural wood constituents. Ann For Sci 64:679-690

51. Zhao H, Lu KP, Lin JG (2015) Effect on properties of Phyllostachysheterocycla Cv Pubescens by heat treatment with oil medium. For Machin Wood Equip 346:14-16

52. Li HT, Su JW, Xiong ZH, Mahmud A, lleana C, Ottavia C (2020) Evaluation on the ultimate bearing capacity for laminated bamboo lumber columns under eccentric compression. Structures 28(12):1572-1579

53. Yang D, Li HT, Xiong ZH, Leonel M, Rodolfo L, lleana C, Ottavia C, Hong CK (2020) Mechanical properties of laminated bamboo under off-axis compression. Compos Part A Appl Sci Manuf 138:10604212

54. Yin Y, Berglund L, Salmén L (2011) Effect of steam treatment on the properties of wood cell walls. Biomacromol 12:194-202

55. Wang QY, Wu XW, Yuan CL, Lou ZC, Li YJ (2020) Effect of saturated steam heat treatment on physical and chemical properties of bamboo. Molecules 25:1999

56. Kubojima Y, Okano T, Ohta M (2000) Bending strength and toughness of heat-treated wood. J Wood Sci 46:8-15

57. Xu GQ, Wang LH, Liu JL, Wu JZ (2013) FTIR and XPS analysis of the changes in bamboo chemical structure decayed by white-rot and brown-rot fungi. Appl Surf Sci 280:799-805

58. Florent L, Marie T, Won-Joung H, Imamura Y, Gril J, Pizzi A (2007) Effect of an oil heat treatment on the leachability and biological resistance of boric acid impregnated wood. Ann For Sci 64:673-678

\section{Publisher's Note}

Springer Nature remains neutral with regard to jurisdictional claims in published maps and institutional affiliations.

\section{Submit your manuscript to a SpringerOpen ${ }^{\circ}$ journal and benefit from:}

- Convenient online submission

- Rigorous peer review

- Open access: articles freely available online

- High visibility within the field

Retaining the copyright to your article

Submit your next manuscript at springeropen.com 